Dynamics of knowledge production and technology diffusion:

Insights from the emergence of wind energy

Cristina Sousa

Nuno Bento

Margarida Fontes

Dezembro de 2014

WP n. 0 2014/09

DOCUMENTO DE TRABALHO

WORKING PAPER

DINAMIP'CET

CENTRO DE ESTUDOS SOBAEA MUDANCA

ISCTE-IUL 


\section{DINAMIP'CET}

CENTRO DE ESTUDOS SOBRE A MUDANCA

SOCIOECONÓMICAE O TERRITÓRIO

ISCTE-IUL

\section{Dynamics of knowledge production and technology diffusion: Insights from the emergence of wind energy}

Cristina Sousa *

Nuno Bento **

Margarida Fontes $* * *$

WP n. ${ }^{\circ} 2014 / 09$

DOI: 10.7749/dinamiacet-iul.wp.2014.09

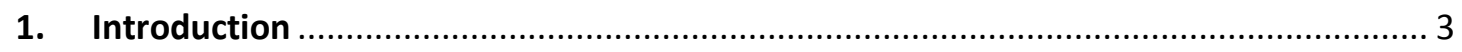





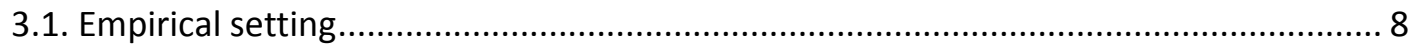

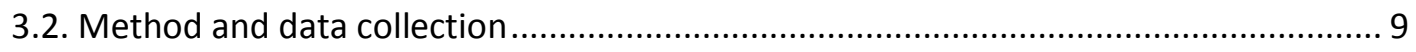

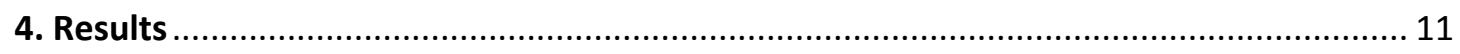

4.1. Long-term trends in scientific publication in wind power .................................... 11

4.2. Technology dynamics and the growth in the publications .................................... 14

4.3. International comparison of publication and capacity growth: the case of Denmark

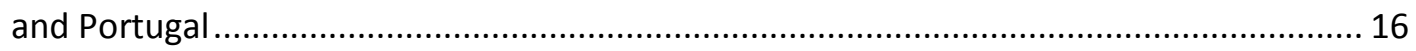

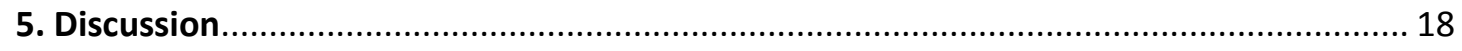

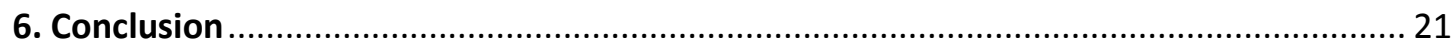



\footnotetext{
* DINAMIA'CET-IUL and ISCTE-IUL. Corresponding author cristina.sousa@iscte.pt;

** DINAMIA'CET-IUL. nuno.bento@iscte.pt;

*** LNEG and DINAMIA'CET-IUL. margarida.fontes@Ineg.pt.
} 


\title{
Dynamics of knowledge production and technology diffusion: Insights from the emergence of wind energy ${ }^{1}$
}

\begin{abstract}
The objective of this paper is to contribute to a better understanding of the relation between the dynamics of knowledge production and technology diffusion along the process of emergence of a new technology, as it unfolds in diverse spatial locations. For this purpose, the paper traces the process of knowledge production over time - expressed in the number of scientific publications - and assesses how its dynamics relate with those of technology upscaling and diffusion, for the case of a new renewable energy technology: wind power. It also compares these processes in different spatial areas, looking at similarities and differences in the evolving patterns, in initial markets and follower regions. In order to trace the dynamics of knowledge production we conduct a bibliometric analysis, using data collected from the Thomson Reuters Web of Science database (for the period 1970-2012). In order to trace the diffusion dynamics we use data collected on both unit scale of turbines and installed capacity of wind power (starting in late 1970s), following the empirical scaling methodology. These analyses are conducted at global scale and, subsequently, at a regional scale, for a pioneer (Denmark) and a fast follower (Portugal). The comparison of the outcomes from the bibliometric and the technology growth analyses permits to understand the rhythm and order in which knowledge was created and applied in this particular innovation. It also provides a preliminary account of the interplay between pioneer and fast follower regions.
\end{abstract}

Keywords: innovation systems; technology emergence and diffusion; spatial dynamics; bibliometrics; wind energy.

JEL Codes: O31 Innovation and Invention: Processes and Incentives; O33 Technological Change: Choices and Consequences; Diffusion Processes; O57 Comparative Studies of Countries; Q42 - Alternative Energy Sources.

\footnotetext{
${ }^{1}$ This research is supported by Portuguese funds by FCT - Fundação para a Ciência e a Tecnologia (PTDC/CS-ECS/113568/2009 and the research grant SFRH/BPD/91183/ 2012). Paper presented the 15th International Joseph A. Schumpeter Society (ISS) Conference, 27- 30 July 2014 in Jena.
}

DINÂMIA'CET - IUL, Centro de Estudos sobre a Mudança Socioeconómica e o Território ISCTE-IUL - Av. das Forças Armadas, 1649-026 Lisboa, PORTUGAL Tel. 210464031 - Extensão 293100 E-mail: dinamia@iscte.pt www.dinamiacet.iscte.pt 


\section{Dynamics of knowledge production and technology diffusion: Insights from the emergence of wind energy}

\section{INTRODUCTION}

The articulation between science and technology and their leading role in the innovation process is still unclear. The debate began in the mid-1980s, when the linear models of innovation started to be increasingly questioned by innovation scholars. But despite the existence of a large number of empirical studies (Bonaccorsi and Thoma, 2007), a discussion remains on the relative role of science-based and experience-based learning in innovation processes. This issue has namely been raised in the case of the emergence and diffusion of renewable energy technologies (Grubler and Wilson, 2013; Hendry and Harbone, 2011; Nemet, 2009; Grubb, 2004).

The objective of this paper is to contribute to this debate, by investigating the relation between the dynamics of knowledge production and technology diffusion along the process of emergence and development of a new energy innovation system, focusing on the case of wind energy technology. More specifically, the paper investigates the process of scientific publication on wind energy over time and assesses how it relates to the growth of wind power installed capacity. It also compares these processes in different spatial areas, looking at similarities and differences in the evolving patterns in initial markets and follower regions.

Wind energy technologies have long been around. But the actual development of a wind innovation system only took place in the last decades of the XX century, as a result of growing environmental concerns that led to pressures for reducing dependency on fossil fuels for energy production (Verbong et al, 2008). Several governments introduced policies promoting renewable energy production, which reduced the technological and market uncertainty associated with the new technologies and protected them from the competition with established technologies, thus effectively boosting their development and market introduction (Jager-Waldau et al, 2011; Lund, 2009;). Wind energy technology emerged as the fastest to reach enough technological maturity to enter the electricity production market and achieve some diffusion, particularly in some countries (McDowall et al., 2013; Lewis and Wiser, 2007; Jacobsson and Johnson, 2000), being currently close to reach cost parity with conventional technologies in some locations (GWEC, 2013).

Thus, a wind energy technological innovation system has emerged and is undergoing fast growth (Gallagher et al, 2012). Since energy policies have targeted both scientific knowledge production and market diffusion, potentially accelerating both, wind energy technology emerges as a particularly interesting setting to investigate their interplay along the development of the innovation system.

DINÂMIA'CET - IUL, Centro de Estudos sobre a Mudança Socioeconómica e o Território ISCTE-IUL - Av. das Forças Armadas, 1649-026 Lisboa, PORTUGAL 


\section{Dynamics of knowledge production and technology diffusion: \\ Insights from the emergence of wind energy}

\section{CONCEPTUAL BACKGROUND}

The Schumpeterian perspective of the process of technological change inspired the creation of the linear model of innovation, where innovation is regarded as almost mechanistic succession of distinct phases. According to this model, there is a set of knowledge production activities, namely $R \& D$, whose results affect directly and sequentially the subsequent phases of the process: innovation and diffusion.

Within this linear view, it is possible to find two theories associated with different stimuli to the innovation process: demand/market pull and technology push. According to demand/market pull theories, the impetus for innovation comes fundamentally from the market, where the innovative firm can detect certain signals (prices, quantities, costs, existing needs and preferences) that guide innovation. According to technology push theories, the fundamental impulse for innovation comes from the scientific and technological system and thus from R\&D activities.

The linear vision, and particularly the technology push model, dominated the thinking about technological change for several decades. Consequently, the dominant view was that innovation is strongly driven by (basic) research and that technological developments are dependent on advancements in science.

In the late 1980s, with the emergence of Kline and Rosenberg's chain-linked model (Kline and Rosenberg, 1986), this linear vision started to be increasingly questioned. One of the main criticisms was the lack of feedback and interaction mechanisms between the stages of the innovation process.

Systemic approaches, which emerge in late 1980s, take a step further in the consideration of the complex and interactive nature of innovation processes and highlight the existence of co-evolution processes between science and technology, or between R\&D and technology diffusion. The literature on systems of innovation considers the existence of a non-linear interaction between science and technology and that innovation is embedded in a wider socio-economic context, where commercialization must also be taken into account (Lundvall et al, 2002).

According to the systemic approach, innovation must be considered as an interactive process. It involves networks of actors (e.g., firms, users, universities), acting within a particular context of institutions and policies that influence knowledge production, technological development, adoption behavior and performance, bringing new products, processes and organization structures into economic use (Jacobsson and Bergek, 2012, Carlsson and Stankiewicz, 1991).

DINÂMIA'CET - IUL, Centro de Estudos sobre a Mudança Socioeconómica e o Território ISCTE-IUL - Av. das Forças Armadas, 1649-026 Lisboa, PORTUGAL Tel. 210464031 - Extensão 293100 E-mail: dinamia@iscte.pt www.dinamiacet.iscte.pt 


\section{Dynamics of knowledge production and technology diffusion: Insights from the emergence of wind energy}

In this paper, we draw on the Technological Innovation Systems (TIS) perspective, considering that it provides an adequate framework to addresses the interactive nature of the process of emergence and growth of new energy innovation systems (Jacobsson and Bergek, 2012, Carlsson and Stankiewicz, 1991: Gallagher et al., 2012; Markard et al., 2012; Grubler et al., 2012). This approach focus on the emergence and diffusion of one technology (which defines the frontier of the system) and considers its development process takes place within a particular innovation system whose main components are actors, institutions and networks (Jacobsson and Johnson, 2000) and addresses the institutional and organizational changes that are needed for these processes to successfully unfold (Markard et al., 2012). Actors need to get the technology ready and aligned with the relevant institutions (Jacobsson, 2008). Along this process they have to fulfill a number of key functions or processes that are required for the TIS to start, grow and gain momentum: development of formal knowledge, direction of search, entrepreneurial experimentation, resource mobilization, materialization, market formation, legitimation, development of positive externalities. These functions are interdependent and changes in one influence the performance of the other.

Bergek et al. (2008) distinguish between a formative phase, where constituent elements of the new TIS begin to be put into place; and a growth phase where the system starts to expand and large-scale technology diffusion takes place through wider market formation and resource mobilization. Because new technologies face high uncertainties and financial needs, in combination with low institutional support and small (if any) markets (Kemp et al, 1998), the formative phase is crucial to build the supportive structure that allows the innovation system to move into the next stage and develop in a self-sustaining way. It has also been pointed out that key functions are likely to change over time, with formal knowledge development and direction of search being critical in the early formative period, whereas market formation becomes more important in more advanced stages (Hekkert and Negro, 2009).

The two phase framework is applied to the analysis of the wind energy innovation system by Bergek and Jacobsson (2003). They describe a first "phase of experimentation" (1975-1989), characterized by technological variety and uncertainty (ie. the technology is not yet stabilized requiring substantial development and experimentation) and by the entry of new firms that are experimenting with the technology in niches, while the market is still underdeveloped. This is followed by a "phase of turbulence and growth" (1990-1999). Once a design (the horizontal-axis three-bladed) is selected among the different alternatives, there is a rapid market growth in terms of installed capacity and the up-scaling of the turbines. There is some early turbulence in terms of actor entry and exit. The entry of large firms bring 


\section{Dynamics of knowledge production and technology diffusion: Insights from the emergence of wind energy}

additional resources and increased legitimacy, potentially driving subsequent growth. The authors also point out that although the different countries analysed (Denmark, Germany and Sweden) went through these phases, the functional patterns varied between them.

This evolution is also depicted by the empirical literature on historical dynamics of scaling in energy technologies (Wilson, 2009), which describes: a formative phase consisting on the experimentation and production of many small scale units in order to establish the first production base; an up-scaling phase by constructing ever larger units to gather technological economies of scale at unit level; and a growth phase characterized by mass production of large-scale units, reaping economies of scale and learning economies at the manufacturing level. Bento and Fontes (2014) argue that by framing these results using the TIS approach it is possible to reach a more complete understanding of the processes taking place: in the formative phase both technology and structures of the innovation system co-evolve and prepare the up-scaling that is necessary in order to move into the large-scale diffusion.

TIS development processes do not occur simultaneously in all countries. Typically, some countries lead the production of new knowledge and/or the technology implementation; others only enter the system when the technology is already diffusing. Previous empirical research on the diffusion of energy technologies found that the patterns of technology vary spatially. In the initial markets where the diffusion begins, growth tends to be slower and stabilizes at a higher extent; however, in the next markets, it tends to accelerate and reach more rapidly saturation but at lower level (Grubler, 1990, 2012). This acceleration of growth as new technologies move from the region where they first developed (core) to new regions (followers) was explained by the fact that the latter adopt a more mature technology, avoiding the costs associated with early knowledge development and experimentation. In this sense, the conditions for a successful emergence of the technology system can be better understood if we take into account the spatial dimension (Binz et al, 2014; Coenen and Truffer, 2012).

The TIS approach also takes into account the role of policies in the promotion of innovation processes. The recent transformations in the energy systems that led to the emergence of renewable energy technologies were driven by long-term environmental concerns, such as climate change. Since market mechanisms are often adverse to new energy technologies, which tend to be more expensive than fossil fuel based alternatives, the development of the wind technology innovation system has been strongly policy driven (Verbong et al, 2008; Bergek et al, 2013).

Policy intervention accelerated the development and implementation of the technology, through incentives for fast implementation of cleaner technology solutions, even when they were not yet competitive with the established fossil fuel-based systems. These

DINÂMIA'CET - IUL, Centro de Estudos sobre a Mudança Socioeconómica e o Território ISCTE-IUL - Av. das Forças Armadas, 1649-026 Lisboa, PORTUGAL Tel. 210464031 - Extensão 293100 E-mail: dinamia@iscte.pt www.dinamiacet.iscte.pt 


\section{Dynamics of knowledge production and technology diffusion: Insights from the emergence of wind energy}

particular circumstances may have influenced the relation between knowledge production and application, since they promote technological learning (Klaassen et al 2005).

Summing up, the TIS approach considers that actors have to perform a number of functions that are necessary for system formation and growth. The relevance and forms assumed by these functions, namely knowledge production and market formation, depend on the system's phase of development. Countries may step in a specific TIS at different moments and thus they may face different challenges, need to perform different activities and engage in different learning processes. Therefore, it can be proposed that:

- the balance between knowledge production and technology diffusion varies between phases of a TIS development

- core and follower countries exhibit different knowledge production and technology diffusion dynamics and strategies.

In order to address these propositions, the paper raises the following research question: Which is the relation between scientific knowledge production and technology diffusion in the emergence and growth of the wind energy innovation system? More specifically:

1. Which are the dynamics of scientific knowledge production (measured by scientific publication) worldwide and across countries?

2. Which are the patterns of technology diffusion (measured by installed capacity, using historical scaling analysis)?

3. Which is the interplay between scientific publication and technology up-scale?

4. Are there differences in this interplay between countries that stepped in the cycle of innovation in different phases, such as Denmark (core) and Portugal (follower).

DINÂMIA'CET - IUL, Centro de Estudos sobre a Mudança Socioeconómica e o Território ISCTE-IUL - Av. das Forças Armadas, 1649-026 Lisboa, PORTUGAL 


\section{EMPIRICAL SETTING AND METHOD}

\subsection{Empirical setting}

Wind turbines are the core element of wind energy technology. Wind turbine technological development results both from $R \& D$ efforts and from accumulated experience in the production and installation (Klaassen et al 2005).

This technology has a long story of development and experimentation of prototypes in niche markets. The energy shocks of the 1970s led a group of pioneer countries (United States, Denmark, Germany and the Netherlands) to devote large amounts of resources to $R \& D$ activities in wind technologies (Neij and Andersen, 2013). In the early 1990s, the Danish industry started to produce and install larger and more efficient wind turbines, becoming a pioneer in the commercial exploitation of wind energy and experiencing fast growth. In the following years, the market for wind turbines knew an enormous development in other European countries, such as Germany and Spain, guided by the success of the Danish experience ${ }^{2}$.

Garud and Karnøe (2003) identified two models of wind technology development: the R\&D-led "breakthrough" model and the "bricolage" model. The first model, followed in particular by the United States, involved intensive R\&D efforts looking for major breakthroughs in large size turbines, which would make wind energy competitive. Denmark pursued the second model, adopting a more bottom-up strategy focused on experimentation and production of smaller scale wind turbines. Given the success of Denmark, the bricolage model was presented as the most successful. However, recent evidence on the relevance of $R \& D$ in the subsequent development of the Danish wind system (Hendry and Harborne, 2011) called for the reassessment of the balance between bricolage and breakthrough. It is suggested that a focus on $R \& D$ or on experience-based learning may be related to different phases of the TIS.

The development and implementation of wind energy technologies was strongly supported by public policies, targeting both formal knowledge production $(R \& D)$ and market development (Saidur et al, 2010; Agnolucci, 2007). In addition to R\&D subsidies (at country and European level), the market penetration of wind energy was heavily dependent on public incentives, such as feed-in tariffs, fiscal incentives, competitive bidding and priority of access into the grid. But, despite the increased efficiency of the technology, wind energy still did not

\footnotetext{
${ }^{2}$ For a detailed analysis of the evolution of the wind turbine technology see Neij and Andersen (2013).

DINÂMIA'CET - IUL, Centro de Estudos sobre a Mudança Socioeconómica e o Território ISCTE-IUL - Av. das Forças Armadas, 1649-026 Lisboa, PORTUGAL Tel. 210464031 - Extensão 293100 E-mail: dinamia@iscte.pt www.dinamiacet.iscte.pt
} 


\section{Dynamics of knowledge production and technology diffusion: \\ Insights from the emergence of wind energy}

reach cost parity with energy from fossil fuel sources and, thus, the wind energy business remains dependent on government policies and vulnerable to political cycles.

Our empirical analysis contrasts a core region, Denmark and a follower country, Portugal. As mentioned before, Denmark was one of the pioneers in the development and implementation of wind energy technologies, and was the first country to create a successful local market for modern wind turbines, in the 1980s and 1990s. Currently, it is among the largest global exporters of wind turbines and, in 2012, 30\% of the domestic electricity consumption was covered by wind energy, which is the highest share by far in the world (GWEC, 2013).

Portugal registered a very fast penetration of wind energy in the 2000s, initially based on imports of the main equipment (i.e. turbines and blades) from companies in core countries. However, this pattern rapidly changed as the country has gradually increased local production of equipment under license. The rapid growth of the local wind "cluster" was possible due to the establishment of close alliances with international manufacturers and the deployment of existing local competences in related sectors such as energy, engineering and industrial activities in complementary fields (Bento and Fontes, 2013). Currently, the country has the second highest share of wind energy in electricity consumption in Europe: over 20\% in 2013 (DGEG, 2014).

\subsection{Method and data collection}

In order to trace the dynamics of knowledge production we conducted a bibliometric analysis, using data collected from the Thomson Reuters Web of Science database.

Keyword based search was used to collect the publication data, using the search query "wind power*, wind energy*" in titles, abstracts and keywords. We have considered all publication types (articles, proceedings, reviews, book chapters, etc) in all languages and all subject categories, both in the Journals of Science Citation Index (SCI) and in the Social Science Citation Index (SSCI).

The resulting publications (33862) included a wide number of studies in scientific areas not related with wind technology, namely in astrophysics and geophysics. In order to correctly capture the dynamics of knowledge production in this field we have checked all publications by title and keywords and, if still in doubt, by abstract, to determine whether the publication effectively focused on wind energy technology. Two field experts from the Portuguese National Laboratory on Energy and Geology (LNEG) then validated the final list of keywords. A total of 11061 publications were identified in this manner.

DINÂMIA'CET - IUL, Centro de Estudos sobre a Mudança Socioeconómica e o Território ISCTE-IUL - Av. das Forças Armadas, 1649-026 Lisboa, PORTUGAL 


\section{Dynamics of knowledge production and technology diffusion: Insights from the emergence of wind energy}

Bibliometrics has been used to understand past technological development and even to forecast emerging technologies (Daim et al, 2006). Scientific publications are an important element of the development of formal field-specific knowledge, namely new knowledge pushing technology frontiers. It is nevertheless recognized that bibliometric studies do not capture all knowledge production. In fact, they leave out tacit components and knowledge produced by companies that wish to maintain it as secret/proprietary.

In order to trace the technology diffusion dynamics, we employ the empirical scaling methodology (Wilson, 2009, 2012; Wilson and Grubler, 2011). The term 'scaling', as used in this context, represents the technological growth that is both rapid and extensive and occurs at multiple levels: the technology unit and the industry as a whole. This method has been used to investigate common patterns in the duration and extent of growth across a range of energy technologies.

Technologies' temporal development and diffusion varies over time and is often represented with a S-shaped curve, which finds a wide support in historical evidence, namely in the case of energy technologies (Grubler, 2012, 1990; Grubler et al., 1999). The main procedure consists of comparing the extent of growth and the duration of diffusion, by graphical inspection or using logistic functions. ${ }^{3}$ In the case of a single technology, this analysis focuses on the growth of unit capacity and the evolution of installed capacity over time.

In addition, the patterns of technology growth also vary spatially. Therefore, the global technology deployment data is often disaggregated by spatial regions, which are distinguished according to the sequence of countries or regions participation in the widespread (spatial) diffusion. In this case, we investigate the differences in technology dynamics in the core (Denmark) and in a rapid follower in this technology (Portugal).

We use data collected on both unit scale of turbines and installed capacity (megawatts, MW) of wind power, for the countries under analysis and globally, starting in late 1970s, when the diffusion of modern wind turbines begun. Following the scaling methodology, we use cumulative figures to express technology deployment, instead of (net) capacity additions, because the former contain the whole history of capacity evolution and are not affected by changes in capital turnover like replacements or substitutions (cf. Wilson,

\footnotetext{
${ }^{3}$ The technological growth is often examined with the help of the three-parameter logistic functions. These models are used to fit actual numbers - either in turbine size and in installed capacity - and to distillate historical patterns in the growth of energy technologies (Grubler, 1998, 2012; Marchetti and Nakicenovic, 1979). This procedure allows the estimation of key parameters of diffusion, which can be compared across technologies and countries: saturation level $(K)$; the inflection point $\left(t_{0}\right.$ coinciding with the point of maximum growth, i.e. F50\%); and the duration of growth ( $\Delta$ t referring to the time length between $\mathrm{F} 1 \%$ and $\mathrm{F} 50 \%$ ).
}

DINÂMIA'CET - IUL, Centro de Estudos sobre a Mudança Socioeconómica e o Território ISCTE-IUL - Av. das Forças Armadas, 1649-026 Lisboa, PORTUGAL 


\section{Dynamics of knowledge production and technology diffusion: Insights from the emergence of wind energy}

2009, 2012). Beyond the comparison with the evolution of maximum unit capacity, cumulative total capacity is also compared to the share of wind energy in final electricity consumption, an indicator of the expansion of the energy services delivered which gives the contribution of the technology to the transformation of the energy system.

Historical time series were compiled from official statistics such as IEA, Danish Energy Agency, Portuguese national statistics, Portuguese General-Directorate for Energy and Geology (DGEG) as well as from information published in secondary sources (e.g., scientific articles, reports).

\section{RESULTS}

This section analyses and compares the dynamics of scientific knowledge production and technology diffusion. These analyses are conducted at global scale and for the initial markets (i.e., the core, which coincides with global data in the early years of diffusion), and subsequently, at a more regional scale through the comparison between the growth in Denmark (core) and in Portugal (follower).

\subsection{Long-term trends in scientific publication in wind power}

To capture the dynamics of knowledge production in the wind field, we present data on the evolution in the number of scientific publications as well as on the countries where they originated from. Figure 1 shows that scientific knowledge production specifically mentioning "wind energy" or "wind power" was residual until the 1980s. Then, the number of publications started to grow, first slowly, but taking off in the early 2000s.

Figure 1 - Evolution of the number of scientific publications in the wind field

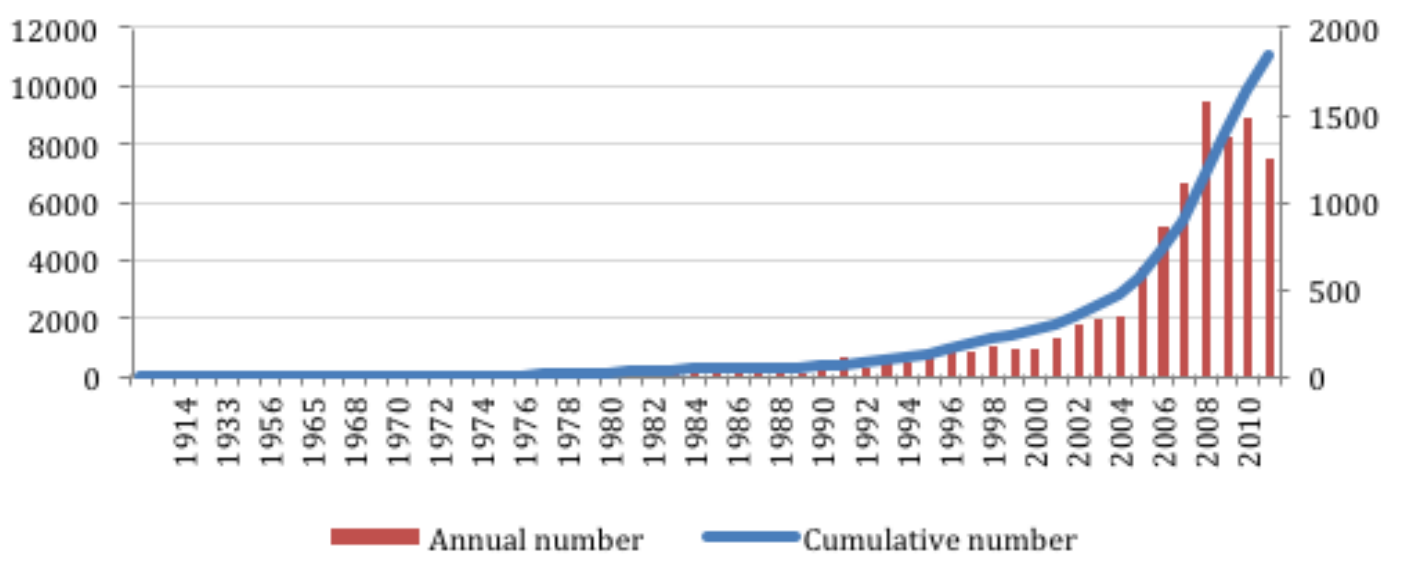

DINÂMIA'CET - IUL, Centro de Estudos sobre a Mudança Socioeconómica e o Território ISCTE-IUL - Av. das Forças Armadas, 1649-026 Lisboa, PORTUGAL Tel. 210464031 - Extensão 293100 E-mail: dinamia@iscte.pt www.dinamiacet.iscte.pt 
Dynamics of knowledge production and technology diffusion:

Insights from the emergence of wind energy

Figure 2 - Evolution of the number of countries with wind publications

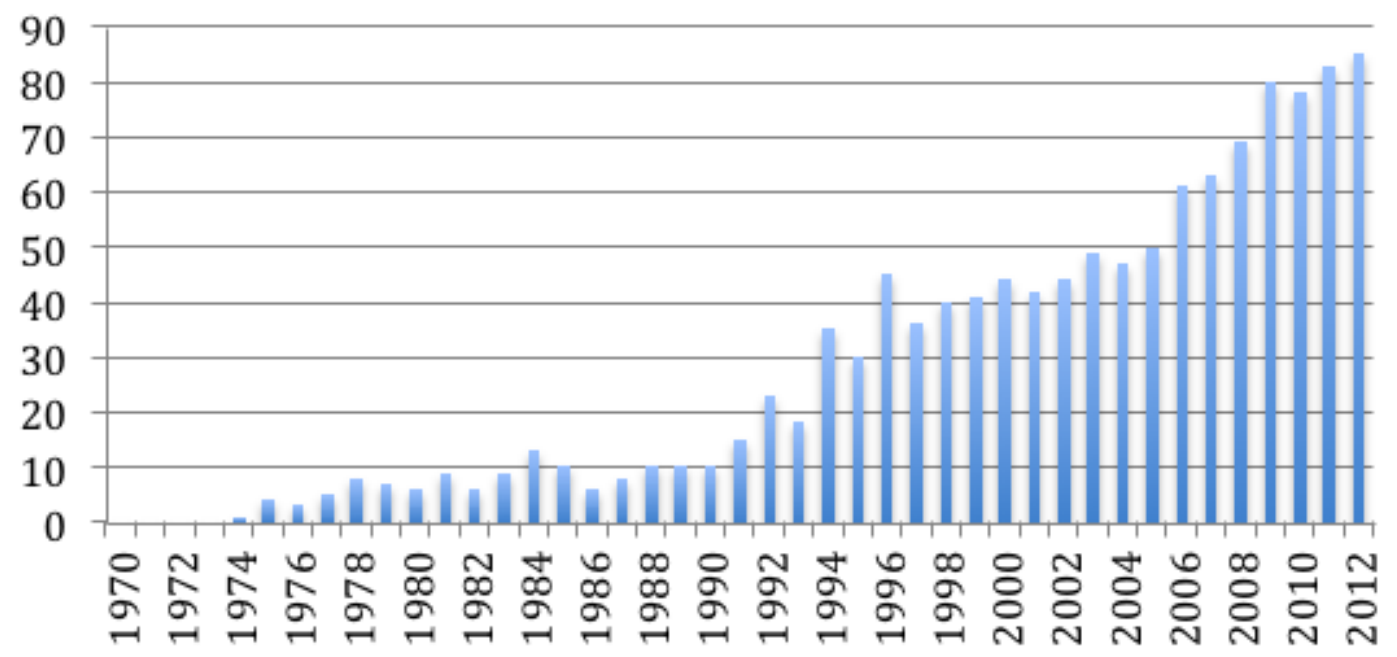

Figure 3 - Evolution of publications involving international co-authorships

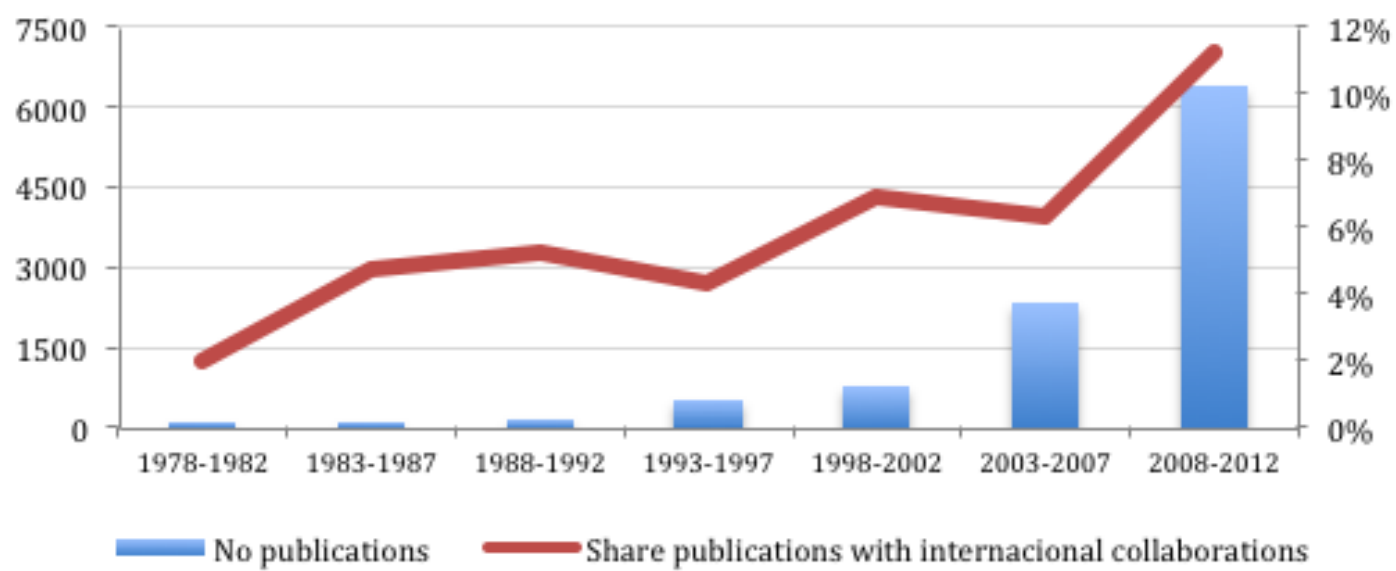

Until the 1990s, only a very small number of countries published in this field (about 10), but their number registered a sustained increase as depicted in Figure 2. This evolution also involved a raise in the number of international co-authorships (Figure 3).

DINÂMIA'CET - IUL, Centro de Estudos sobre a Mudança Socioeconómica e o Território ISCTE-IUL - Av. das Forças Armadas, 1649-026 Lisboa, PORTUGAL 
Dynamics of knowledge production and technology diffusion:

Insights from the emergence of wind energy

Figure 4 - Share of the countries in the annual number of publications

1988-1992

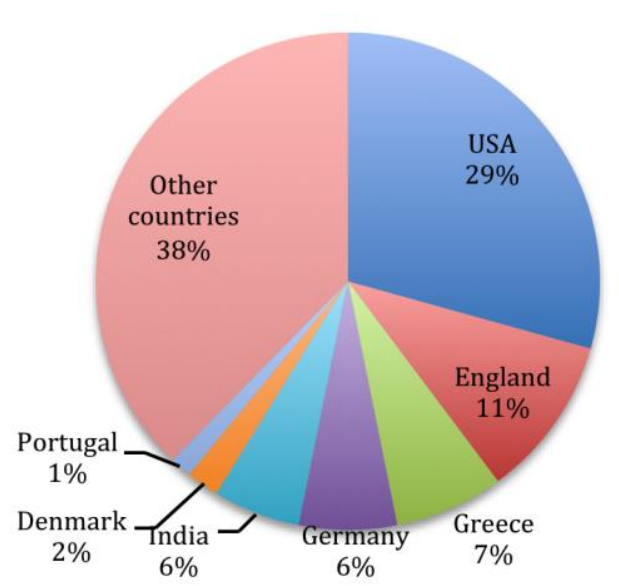

1998-2002

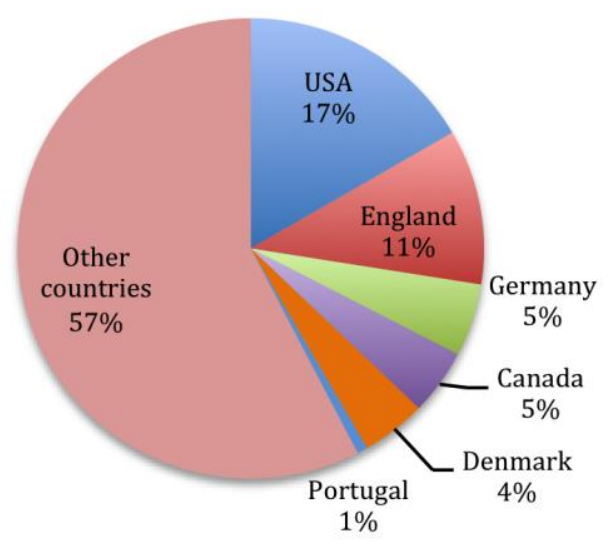

1993- 1997

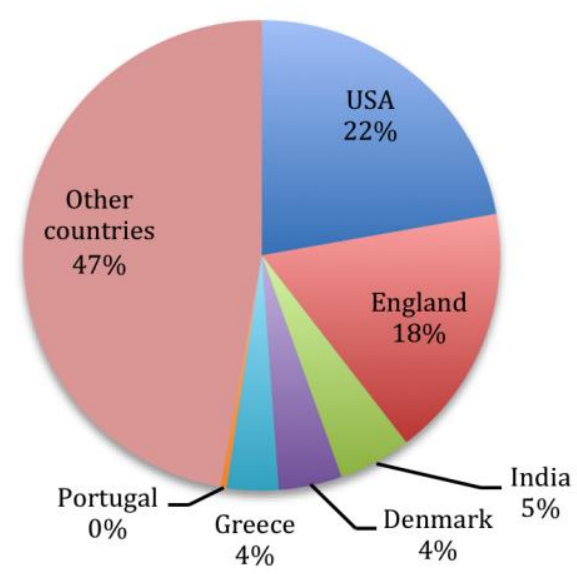

2003-2007



2008-2012

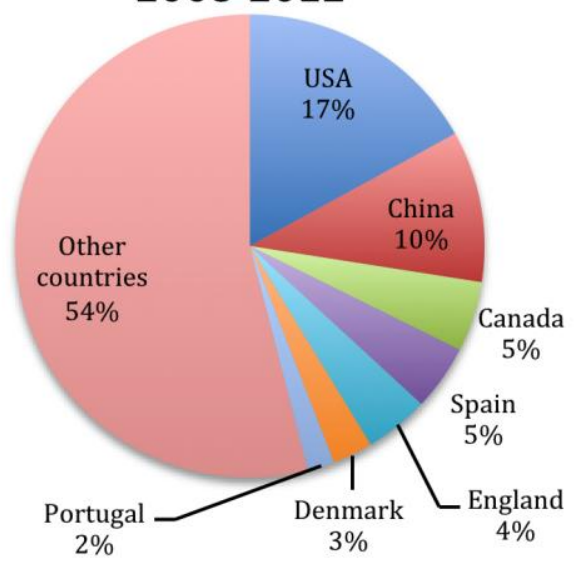

Figure 4 presents the share of the top 5 countries, plus Denmark and Portugal, over time, using 5-year periods. It shows that there was some regional reconfiguration of the leading

DINÂMIA'CET - IUL, Centro de Estudos sobre a Mudança Socioeconómica e o Território ISCTE-IUL - Av. das Forças Armadas, 1649-026 Lisboa, PORTUGAL

Tel. 210464031 - Extensão 293100 E-mail: dinamia@iscte.pt www.dinamiacet.iscte.pt 


\section{Dynamics of knowledge production and technology diffusion: Insights from the emergence of wind energy}

knowledge producers, notably the emergence of China and the decline of England. The United States remain the main actor throughout the period.

\subsection{Technology dynamics and the growth in the publications}

There is a growing body of literature on the effects of technology implementation and the associated learning on the development of the wind innovation system. But, surprisingly, previous research did not address the relationship between the dynamics of technology and the evolution of scientific production.

In order to address this question, the evolution of the annual installed capacity worldwide and the evolution in the number of publications are compared in Figure 5. The data reveal that both capacity and publications have increased since the early 1990s, but the former at a slightly faster pace than the latter.

\section{Figure 5 - Growth of capacity additions (MW) and of the number of annual publications worldwide since 1977, semi-log scale.}

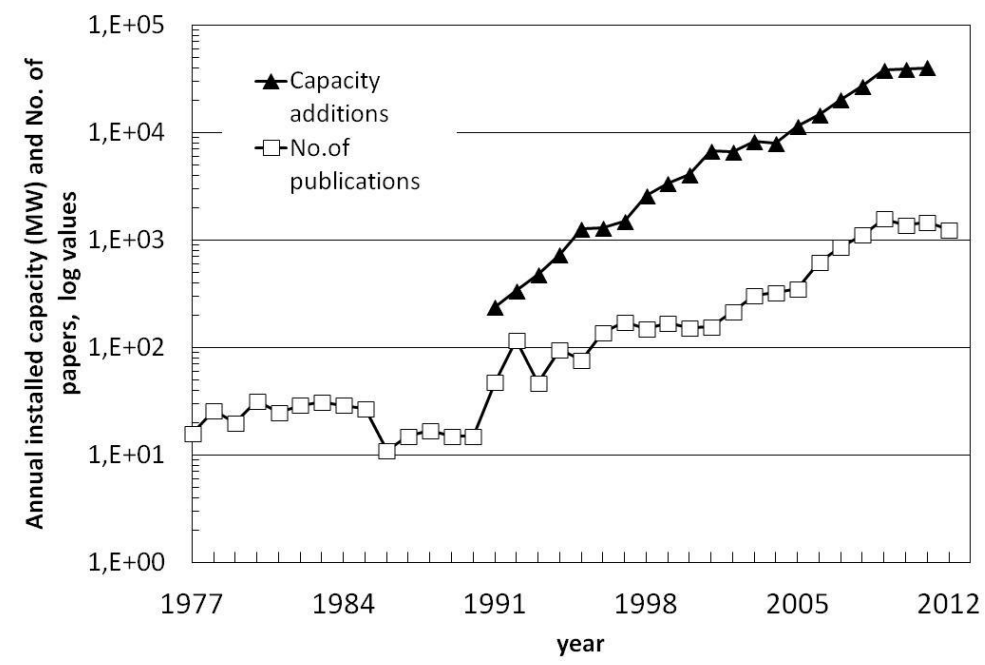

The relationship between scientific (published) knowledge and both technology and market scaling is examined in more detail in Figure 6. As pointed out above the literature refers to stages or phases in technology development and diffusion. However, it is unclear from both the theoretical and empirical literature whether the early stages are mainly driven by the results of learning associated with technology implementation, or by the development of formal knowledge.

The growth in the number of scientific publications is compared with indicators of technology scaling (i.e. cumulative installed capacity and maximum size of wind turbines in the core market, Denmark) in order to gain some insights about the main drivers of the wind 
innovation system development (Figure 6). In addition, these figures are compared against the growth of the share of wind power in final electricity consumption in the core. This is a new indicator of technology scaling in terms of services provided, i.e. final energy supply.

Figure 6 - Three-stages sequential process of wind energy technologies



DINÂMIA'CET - IUL, Centro de Estudos sobre a Mudança Socioeconómica e o Território ISCTE-IUL - Av. das Forças Armadas, 1649-026 Lisboa, PORTUGAL

Tel. 210464031 - Extensão 293100 E-mail: dinamia@iscte.pt www.dinamiacet.iscte.pt 


\section{Dynamics of knowledge production and technology diffusion: \\ Insights from the emergence of wind energy}

The analysis of the figures confirms the existence of a three-stages process that has been suggested in recent studies (Wilson, 2009, 2012) regarding the diffusion of wind power. There is a strong growth of both the share of wind energy in final electricity consumption in Denmark, and the number of publications worldwide right after the end of the up-scaling phase (i.e. around 2002 when the size of the largest commercialized turbines stabilize in 3 MW). The share of wind in the electricity mix moves from $12 \%$ to $28 \%$ between 2002 and 2011, benefiting from the simultaneous growth of the size of the turbine and the number of installations that led to a boost in the installed capacity, as shown in the upper graph. This share had already increased from 2\%, since the beginning of the formative phase, in 1990. The number of publications takes-off when wind energy is well into the growth stage in the core (even if it has risen slightly in the previous period).

Therefore, this result seems to indicate that the dynamics of scientific production (at world level) started after the improvement of the technology and the development of the first markets in the core. Yet there are a number of reasons that may partly explain part this delay in the production of scientific knowledge, such as normal lags related to paper publication and the fact that at the end of the up-scaling phase the technology starts diffusing to other countries (e.g. in Portugal as analyzed in the next section), which contributes to further push up the number of publications.

\subsection{International comparison of publication and capacity growth: the case of Denmark and Portugal}

In this section we investigate if there are differences in terms of both technology and scientific production dynamics between countries that stepped into the wind energy in different phases. The patterns of growth of both the number of scientific publications and installed capacity for Denmark (core) and Portugal (follower) are shown in Figure 7.

In Denmark, the installed capacity grew much more rapidly than the cumulative number of publications, during a large part of the 1990s. The latter accelerates in the 2000s, reflecting the slower, but gradual, increase of the annual number of publications.

In Portugal, the evolution of the installed capacity and the evolution of the cumulative number of publications are similar. Contrary to Denmark, there is not, in the 2000s, a steady progression in the annual number of publications.

A comparative analysis of the relationship between the cumulative number of publications and the cumulative installed capacity for Denmark and Portugal reveals two different dynamics, with market development clearly preceeding the rise in publications in the 


\section{Dynamics of knowledge production and technology diffusion: Insights from the emergence of wind energy}

case of Denmark, whereas technology implementation and knowledge production co-evolve in the case of Portugal.

Figure 7 - Annual and cumulative number publications versus cumulative installed capacity, in Denmark (top) and Portugal (bottom)
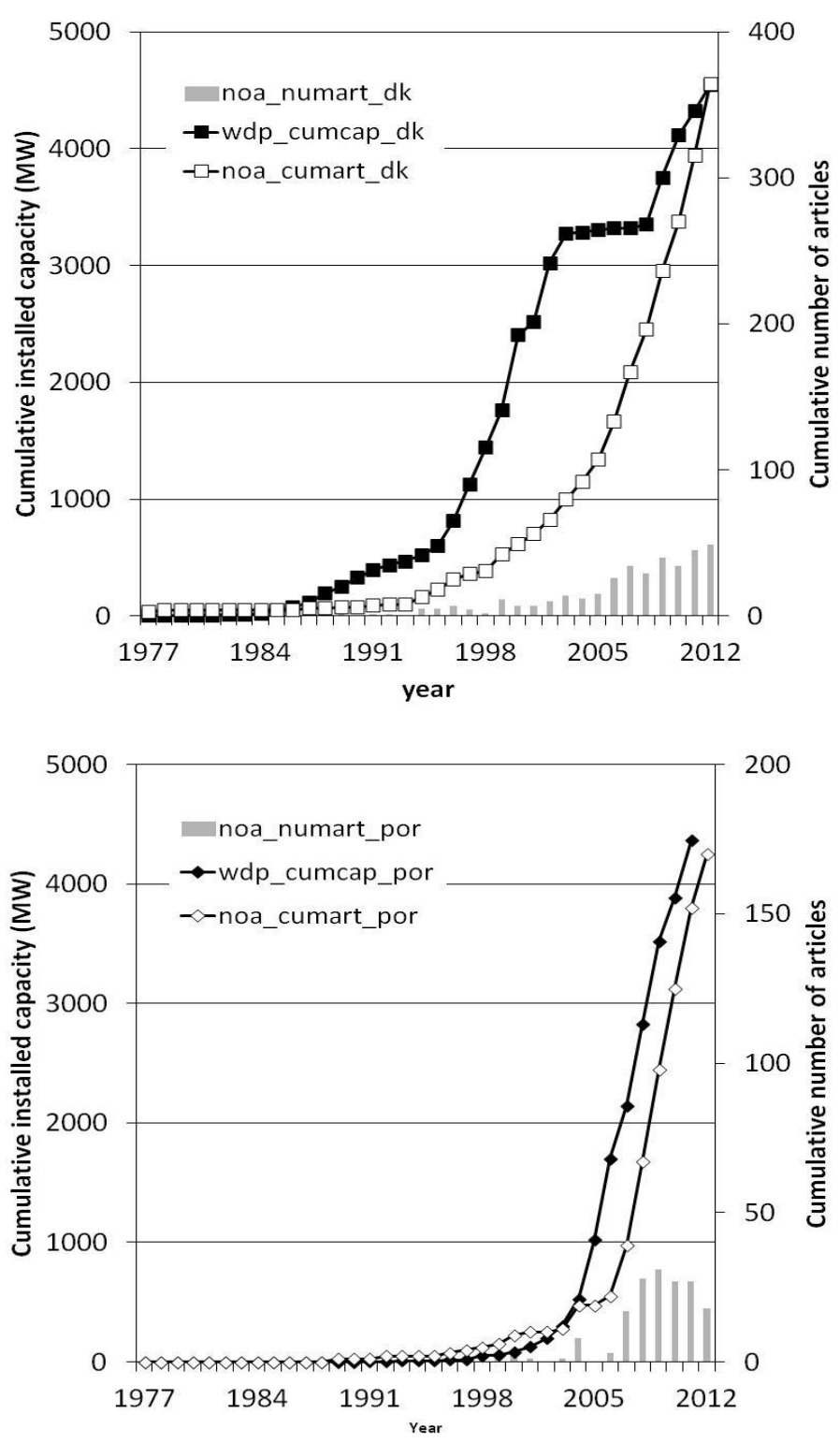

The effect of technology deployment in terms of the rise in the share of wind energy in the final electricity consumption of both countries is presented in Figure 8. These figures are further compared to the worldwide number of publications - considered here as a proxy of the global pool of knowledge. Results show that the part of wind in the electricity mix in Denmark preceeded the increase in the number of papers published. In contrast, the rise of 


\section{Dynamics of knowledge production and technology diffusion: Insights from the emergence of wind energy}

share of the wind electricity in Portugal took place after the take-off in worldwide scientific publication.

All in all, the analysis suggests that the implementation and operation of the first wind farms in the follower country benefited from the availability of codified knowledge at the global level. Conversely, the results obtained for Denmark suggest that the technical problems faced in the early years had to be solved with experimentation (very important during the upscaling stage) and the creation of new knowledge (i.e. more problem-driven type of knowledge), whereas in Portugal the focus was more on the creation of capacity to adopt, use and diffuse the new technology (Bento and Fontes, 2013).

\section{Figure 8 - Share of wind energy in national electricity mixes and publication dynamics}

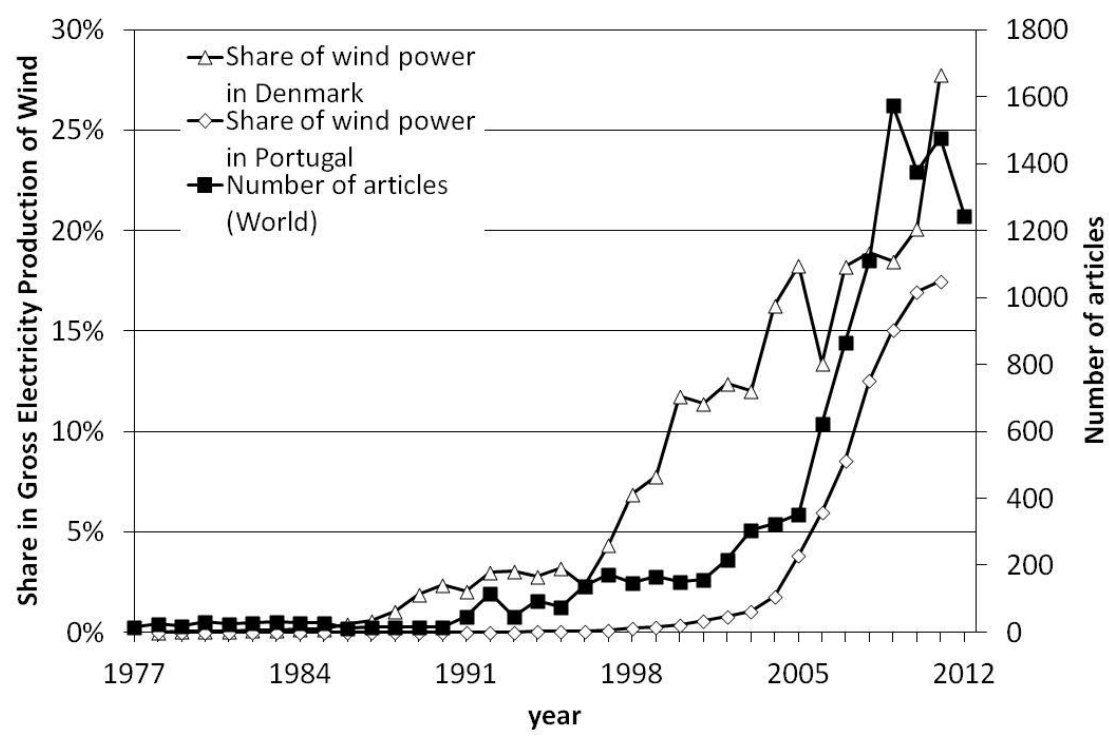

\section{DISCUSSION}

As was stressed in section 2, there is still a debate on the articulation between R\&D-based learning and implementation-based learning in wind technology. The TIS literature has suggested that the balance between these two forms of learning is influenced by the stage of development of the TIS. The results presented in the previous section show that the development process of the wind TIS occurred in three phases. This in line with the evidence presented by empirical literature on the historical dynamics of scaling the diffusion of technology (Wilson, 2009; 2012). However, our results show that these phases can be observed, not only when we consider the diffusion of the technology, but also when we consider the production of formal knowledge. 


\section{Dynamics of knowledge production and technology diffusion: Insights from the emergence of wind energy}

The results also show that, as proposed in the beginning of the paper, there are differences in the dynamics of knowledge production and of technology diffusion along the process of development of the wind innovation system. In fact, it is possible to find a lag between the technology up-scaling at the core and the rise in worldwide scientific publication: the former occurs in the mid-1990s, while the second only occurs in the mid-2000s. Thus, if we consider only the period when the wind innovation system emerged, took-off and achieved some growth in the core countries, it is possible to argue that extensive technology experimentation and development was prior to the growth in formal knowledge production ${ }^{4}$. The latter only effectively took-off when technology was being implemented at a wider scale, potentially raising new problems that required the production of new (scientific) knowledge; and they have co-evolved from then on. The upsurge in scientific publication can be related not only to the need to improve the technology and solve technical problems (namely improve turbine efficiency or address the uncertainty associated with the wind resource), but also to the need to gain knowledge on the socio-economic-political processes associated with the implementation of the technology.

This pattern of development may explain the relevance assumed by a "bricolage" model - where the innovation process is led by technology implementation and the learning processes associated with it (Garud and Karnøe, 2003) - in the country that was pioneer in the development and deployment of the technology that ended-up being widely adopted (Denmark). It may also explain why this model is loosing relevance in Denmark, as suggested by Hendry and Harborne (2011). In fact, our results show a recent increase in the role of formal knowledge production, expressed by scientific publications, a trend also identified by Hendry and Harborne (2011), using data on R\&D projects. Other leading countries, such as the US and UK, that adopted a different model - R\&D led - and thus invested more strongly on formal knowledge production were less successful in the development of a wind innovation system.

These results are in line with the TIS approach, showing that it is relevant to take into account different phases in the development of the innovation system and that different functions may play different roles along the emergence and growth of the system. The results also confirm that the system's development patterns may vary between contexts.

\footnotetext{
${ }^{4}$ This may be partly explained by the nature of the knowledge required to develop wind conversion technologies. According to Bergek and Jacobsson (2003) the knowledge base underlying turbine technology is mechanical and electrical engineering mixed with software and aerodynamics.
}

DINÂMIA'CET - IUL, Centro de Estudos sobre a Mudança Socioeconómica e o Território ISCTE-IUL - Av. das Forças Armadas, 1649-026 Lisboa, PORTUGAL Tel. 210464031 - Extensão 293100 E-mail: dinamia@iscte.pt www.dinamiacet.iscte.pt 


\section{Dynamics of knowledge production and technology diffusion: Insights from the emergence of wind energy}

This may be particularly the case for countries that enter the system in different phases. In fact, the results obtained for the case of Portugal - as a follower country - suggest the existence of a third model in the development of the wind innovation system, where R\&D-led learning and implementation-led learning closely co-evolve.

Portugal has entered the wind innovation system at a period when the technology was already in a more developed stage. There was already a substantial scientific knowledge pool available to the followers. But the results for Portugal show that the increase in installed capacity co-evolved with the production of new formal knowledge. This fact can be explained:

- by the need to develop absorptive capacity: thus the increase in publication before the diffusion of the technology (until the beginning of the 2000s)

- by the need to generate knowledge related with the implementation of wind technology in the specific locations (including wind assessment models and studies);

- by the need to solve problems related to the implementation of the technology (grid integration, storage, etc.).

Therefore, this case shows that knowledge codified in publications can be considered as a global resource; but the implementation of the technology in real (local) contexts requires specific knowledge and learning processes. This leads to a co-evolution between the production of scientific knowledge and the diffusion of technology. Further research is required to understand the nature of the knowledge produced over time.

DINÂMIA'CET - IUL, Centro de Estudos sobre a Mudança Socioeconómica e o Território ISCTE-IUL - Av. das Forças Armadas, 1649-026 Lisboa, PORTUGAL 


\section{Dynamics of knowledge production and technology diffusion: Insights from the emergence of wind energy}

\section{CONCLUSION}

This paper addressed the relation between the dynamics of knowledge production and technology diffusion along the process of emergence and development of the wind innovation system.

The results can offer some preliminary insights into the process of emergence and growth for a new sustainable energy technology. They uncover different patterns of articulation between knowledge production and technology diffusion along this process, contributing to the understanding of innovation as a complex, non-linear process, encompassing both R\&D-led processes and learning-related processes (from the effective use of the technology)

This research offers a twofold contribution. First, it contributes to the theoretical debate on the articulation between science and technology in innovation processes, since it suggests that context matters. Previous research has shown that the nature of knowledge influences this articulation (Bonaccorsi and Thoma, 2007). We add that, even within the same technology, we can find different patterns over time and over space, that can be explained by the internal dynamics of technology development and by the national policies and actors' strategies.

Second, it provides a novel methodological approach, by combining indicators from two different methods: publications from bibliometrics and technology up-scale from historical scaling analysis.

The results can also offer some preliminary insights for innovation and technology policies aiming to promote the take-off and widespread adoption of sustainable innovations.

The research also raised some questions, namely;

- Which were the strategies adopted by actors in each country, regarding the balance between scientific publication and technology implementation?

- Is the "co-evolution" pattern identified for Portugal common to all countries that enter the wind innovation system in a follower position?

- To what extent are these patterns influenced by the nature of the technology?

- Can we find similar patterns in the emergence and development of an innovation system for other renewable energy technologies (i.e. are there specific patterns of behavior in the strong policy-driven renewable energy field?).

These questions will be explored in further research, both by exploiting the existing data on wind; and by extending the research to other renewable energy technologies (solar, wave, etc.).

DINÂMIA'CET - IUL, Centro de Estudos sobre a Mudança Socioeconómica e o Território ISCTE-IUL - Av. das Forças Armadas, 1649-026 Lisboa, PORTUGAL 


\section{Dynamics of knowledge production and technology diffusion: \\ Insights from the emergence of wind energy}

\section{REFERENCES}

AGNOLUCCI, P., (2007) Wind electricity in Denmark: A survey of policies, their effectiveness and factors motivating their introduction, Renewable and Sustainable Energy Reviews, 11: 951-963.

BENTO, N., and Fontes, M., (2014) The construction of a new technological innovation system in a follower country: wind energy in Portugal, DRUID Society Conference 2014 on Entrepreneurship - Organization - Innovation, 16-18 June 2014, CBS, Copenhagen. [http://druid8.sit.aau.dk/druid/ acc_papers/iu4yovx915h0ceteo9d5nm961xvg.pdf].

BENTO, N. and Fontes, M., (2013) Mechanisms that accelerate the diffusion of renewable technologies in new markets: Insights from the wind industry in Portugal, DINÂMIA'CETWorking Papers, 2013/11, https://repositorio.iscte-iul.pt/bitstream/10071/6624/1/ WP_201311.pdf.

BERGEK, A., Berggren, C., Magnusson, T., and Hobday, M., (2013) Technological discontinuities and the challenge for incumbent firms: Destruction, disruption or creative accumulation? Research Policy, 42: 1210-1224.

BERGEK, A., Jacobsson, S., Carisson, B., Lindmark, S. and Rickne, A., (2008), Analyzing the functional dynamics of technological innovation systems: A scheme of analysis, Research Policy, 37: 407-429.

BERGEK, A., and Jacobsson, S., (2003) The emergence of a growth industry: a comparative analysis of the German, Dutch and Swedish wind turbine industries, in Metcalfe, S. and Cantner, U. (eds.) Change, Transformation and Development, Springer, pp 197-227.

BINZ, C., Truffer, B., and Coenen, L., (2014) Why space matters in technological innovation systems-Mapping global knowledge dynamics of membrane bioreactor technology, Research Policy, 43: 138-155.

BONACCORSI, A., and Thoma, G., (2007) Institutional complementarity and inventive performance in nano science and technology, Research Policy, 36: 813-831.

CARLSSON, B., and Stankiewicz, R., (1991) On the nature, function and composition of technological systems, Journal of evolutionary economics, 1: 93-118.

DINÂMIA'CET - IUL, Centro de Estudos sobre a Mudança Socioeconómica e o Território ISCTE-IUL - Av. das Forças Armadas, 1649-026 Lisboa, PORTUGAL Tel. 210464031 - Extensão 293100 E-mail: dinamia@iscte.pt www.dinamiacet.iscte.pt 


\section{Dynamics of knowledge production and technology diffusion: \\ Insights from the emergence of wind energy}

COENEN, L., and Truffer, B. (2012) Places and Spaces of Sustainability Transitions: Geographical Contributions to an Emerging Research and Policy Field, European Planning Studies, 20: 367-374.

DAIM, T., Rueda, G., Martin, H. and Gerdsriet, P. (2006) Forecasting emerging technologies: Use of bibliometrics and patent analysis, Technological Forecasting and Social Change, 73: 981-1012.

DGEG (2014) Renováveis: Estatísticas Rápidas - abril 2014, Direcção Geral de Energia e Geologia [http://www.dgeg.pt/]

GALLAGHER, K.S., Grubler, A., Kuhl, L., Nemet, G., and Wilson, C. (2012) The Energy Technology Innovation System, Annual Review of Environment and Resources, 37: 137-162.

GARUD, R., and Karnøe, P. (2003) Bricolage versus breakthrough: distributed and embedded agency in technology entrepreneurship, Research policy, 32: 277-300.

GRUBB, M., (2004). Technology Innovation and Climate Change Policy: an overview of issues and options. Keio economic studies, 41(2): 103.

GRUBLER, A., (2012) Energy transitions research: Insights and cautionary tales, Energy Policy 50: 8-16.

GRUBLER, A., (1998) Technology and Global Change, Cambridge University Press, Cambridge, UK.

GRUBLER, A., (1990) The rise and fall of infrastructures. Physica-Verlag, Heidelberg.

GRUBLER, A., F. Aguayo, K. Gallagher, M. Hekkert, K. Jiang, L. Mytelka, L. Neij, G. Nemet and C. Wilson (2012), Chapter 24 - Policies for the Energy Technology Innovation System (ETIS). In Global Energy.

GRUBLER, A., F. and Wilson, C., (Eds.) (2013), Energy Technology Innovation: Learning from Historical Successes and Failures, Cambridge University Press.

GWEC, (2013) Global Wind Report - Annual market update 2012, Global Wind Energy Council, Brussels.

DINÂMIA'CET - IUL, Centro de Estudos sobre a Mudança Socioeconómica e o Território ISCTE-IUL - Av. das Forças Armadas, 1649-026 Lisboa, PORTUGAL Tel. 210464031 - Extensão 293100 E-mail: dinamia@iscte.pt www.dinamiacet.iscte.pt 


\section{Dynamics of knowledge production and technology diffusion: Insights from the emergence of wind energy}

HEKKERT, M. P., and Negro, S. O. (2009) Functions of innovation systems as a framework to understand sustainable technological change: Empirical evidence for earlier claims, Technological Forecasting and Social Change, 76(4): 584-594.

HENDRY, C., \& Harborne, P., (2011) Changing the view of wind power development: More than "bricolage", Research Policy, 40(5): 778-789.

JACOBSSON, S., Bergek, A., (2012) Innovation system analyses and sustainability transitions: Contributions and suggestions for research, Environmental Innovation and Societal Transitions (1): 41-57.

JACOBSSON, S. and Johnson, A., (2000) The diffusion of renewable energy technology: an analytical framework and key issues for research, Energy Policy 28: 625-640.

JACOBSSON, S., (2008) The emergence and growth of a 'biopower' innovation system in Sweden, Energy Policy 36 (4):1491-508.

JÄGER-WALDAU, A., Szabó, M., Scarlat, N., and Monforti-Ferrario, F., (2011) Renewable electricity in Europe. Renewable and Sustainable Energy Reviews, 15: 3703-3716.

KEMP, R., Schot, J., and Hoogma, R., (1998) Regime shifts to sustainability through processes of niche formation. The approach of strategic niche management, Technology Analysis and Strategic Management 10: 175-95.

KLAASSEN, G., Miketa, A., Larsen, K., and Sundqvist, T., (2005) The impact of R\&D on innovation for wind energy in Denmark, Germany and the United Kingdom, Ecological Economics, 54: 227-240.

KLINE, S. J., and Rosenberg, N., (1986) An Overview of Innovation. In Landau, R. \& Rosenberg, N (Eds.) The Positive Sum Strategy, Washington, National Academy Press, pp. 275-305.

LEWIS, J.I., Wiser, R.H., (2007) Fostering a renewable energy technology industry: An international comparison of wind industry policy support mechanisms. Energy policy 35, $1844-1857$.

LUND, P.D., (2009) Effects of energy policies on industry expansion in renewable energy, Renewable Energy 34(1), 53-64.

DINÂMIA'CET - IUL, Centro de Estudos sobre a Mudança Socioeconómica e o Território ISCTE-IUL - Av. das Forças Armadas, 1649-026 Lisboa, PORTUGAL 


\section{Dynamics of knowledge production and technology diffusion: Insights from the emergence of wind energy}

$\overline{\text { LUNDVALL, B.A, Johnson, B., Andersen, E.S., and Dalum, B., (2002) National systems of }}$ production, innovation and competence building, Research Policy, 31: 213-23.

MARCHETTI, C., and Nakicenovic, N., (1979) The dynamics of energy systems and the logistic substitution model, RR-79-13, International Institute for Applied Systems Analysis, Laxenburg.

MARKARD, J., Raven, R., and Truffer, B., (2012) Sustainability transitions: An emerging field of research and its prospects, Research Policy 41(6), 955-967.

MCDOWALL, W., Ekins, P., Radošević, S., Zhang, L.Y., (2013) The development of wind power in China, Europe and the USA: how have policies and innovation system activities coevolved?. Technology Analysis \& Strategic Management 25(2), 163-185.

NEIJ, L. and Andersen, P.D., (2013) A Comparative Assessment of Wind Turbine Innovation and Diffusion Policies, in Grubler, A. and Wilson, C. (Eds.) Energy Technology Innovation. Learning from Historical Successes and Failures, Cambridge University Press: Cambridge, UK, pp. 221-230.

NEMET, G. F., (2009) Demand-pull, technology-push, and government-led incentives for non-incremental technical change. Res. Pol. 38, 700-709.

SAIDUR, R., Islam, M.R., Rahim, N.A. and Solangi, K.H., (2010) A review on global wind energy policy, Renewable and Sustainable Energy Reviews, 14: 1744-1762.

VERBONG, G., Geels, F. and Raven, R., (2008) Multi-niche analysis of dynamics and policies in Dutch renewable energy innovation journeys (1970-2006), Technology Analysis \& Strategic Management, 20: 555-573.

WILSON, C., (2009) Meta-analysis of unit and industry level scaling dynamics in energy technologies and climate change mitigation scenarios. IIASA Interim Report IR-09-029, Laxenburg, Austria.

WILSON, C., (2012) Up-Scaling, Formative Phases, and Learning in the Historical Diffusion of Energy Technologies, Energy Policy 50: 81-94.

WILSON, C., and Grubler, A., (2011) Lessons from the history of technological change for clean energy scenarios and policies. Natural Resources Forum 35, 165-184.

DINÂMIA'CET - IUL, Centro de Estudos sobre a Mudança Socioeconómica e o Território ISCTE-IUL - Av. das Forças Armadas, 1649-026 Lisboa, PORTUGAL Tel. 210464031 - Extensão 293100 E-mail: dinamia@iscte.pt www.dinamiacet.iscte.pt 